Uniwersytet Marii Curie-Skłodowskiej w Lublinie

Wydział Humanistyczny

Instytut Filologii Słowiańskiej

tel.: +48815372668

e-mail: dudek.agnieszka@wp.pl

\title{
Życie i śmierć w świetle inskrypcji nagrobnych nekropolii prawosławnych wschodniej Lubelszczyzny
}

Słowa kluczowe: inskrypcja nagrobna, nekropolie, wschodnia Lubelszczyzna, wyobrażenia o śmierci

Podstawą materiałową artykułu są inskrypcje nagrobne pochodzące z nekropolii prawosławnych i mieszanych (prawosławno-katolickich), a także dawnych greckokatolickich ${ }^{1}$ województwa lubelskiego ${ }^{2}$. Dokumentacja terenowa pochodzi z 15 nekropolii.

Inskrypcja nagrobna jest to krótki napis nagrobkowy, najczęściej wierszowany, a także utwór poetycki sławiący zmarłego, utrzymany w stylu takiego napisu, o kanonicznym szablonie, o elementach stałych i fakultatywnych ${ }^{3}$, będący komunikatem językowym. Utylitarna funkcja inskrypcji polega na informowaniu odbiorcy o śmierci i miejscu pochowania zmarłego oraz na przekazaniu niezbędnych, zdaniem nadawcy, informacji o jego życiu.

1 Współcześnie czynny jest jeden cmentarz należący do parafii greckobizantyjskiej (neounickiej) w miejscowości Kostomłoty, powiat bialski [Czyżewski 2013, XIV].

2 Materiał został zebrany w ramach grantu własnego pt. Strukturalno-semantyczny opis nekropolii prawosławnych Lubelszczyzny nr 1 H01D 00929 pod kierownictwem prof. dr. hab. F. Czyżewskiego.

3 Do informacji stałych należą imię i nazwisko, data urodzenia i śmierci, do elementów fakultatywnych zawód, miejsce urodzenia, posłanie, cytaty z Biblii, modlitwy, dodatkowe informacje o zmarłym. 
Współczesna inskrypcja charakteryzuje się skrótowością, podyktowaną najczęściej względami ekonomicznymi, dążeniem do zacierania indywidualności przez stereotypizację, głoszeniem ogólnych prawd filozoficznych, moralnych, etycznych. Jest ponadto wyrazem poglądów religijnych dotyczących najczęściej wiary w Boga, postaw wobec rzeczy ostatecznych, manifestowaniem przynależności do określonej społeczności wyznaniowej czy światopoglądowej [Długosz 2010, 15; 37-38]. Dla szeroko pojętej kultury inskrypcje są świadectwem określonego sposobu patrzenia na świat, ujmowania rzeczywistości, wierzeń czy wyobrażeń religijnych. Jak zauważa Władysław Kupiszewski, inskrypcje zawierające filozoficzne refleksje nad życiem i śmiercią, wierzenia i wyobrażenia religijne są znamienne dla całej Polski, jednak na jej wschodnich terenach występują znacznie częściej [Kupiszewski 1986, 27, 30]. Analiza napisów nagrobnych pozwala więc na odtworzenie sposobu postrzegania życia i śmierci, wiary w nieśmiertelność i zmartwychwstanie.

Wśród fakultatywnych elementów inskrypcji liczną grupę stanowią napisy nawiązujące do aksjologii rodzinnej [por. Steczko 2011, 24-25]. Zważywszy na fakt, że w inskrypcji umieszcza się tylko informacje najważniejsze, najbardziej, zdaniem nadawcy, istotne [Długosz 2010, 196], za istotny aspekt życia doczesnego człowieka fundatorzy uznaja pełnione za życia role w rodzinie. W tego typu napisach dodatkowo podkreśla się stosunek do zmarłych poprzez używanie określeń nacechowanych emocjonalnie, wartościujących pozytywnie, np. najlepsza, najdroższy, ukochany, kochany, dobry, najmilsza itp. Także apelatywy rzeczownikowe określające pokrewieństwo między zmarłym i fundatorami mogą mieć zabarwienie emocjonalne; służy temu stosowanie form hipokorystycznych, np. tatuś, córunia itp. Oto przykłady takich inskrypcji:

\section{ZAB-6966}

Ś.P. MARIA IWANIUK ZM.2.XI.1996 R. W WIEKU 86 LAT SYBIRACZKA CZŁOWIEK WIELKEGO SERCA I SKROMNOŚCI

NAJLEPSZA MATKA. POZOSTANIE W NASZEJ PAMIĘCI JAKO WZÓR HARTU DUCHA, NIEZŁOMNOŚCI I WIARY. BOŻE MIEJ JĄ W OPIECE

\section{BP-I-2911}

Ś.P. MIKOŁAJ WOJTOWICZ ŻYŁ LAT 63 ZM. 21-IV-1975 r. POKÓJ JEGO DUSZY Najdroższemu mężowi i tatusiowi żona $i$ dzieci

\section{BP-I-2942}

Ś.P. JAN BUCHARZEWSKI ŻYŁ LAT 74 ZM. DN. 6-I-1931 R. POKÓJ JEGO DUSZY UKOCHANEMU OJCU SYN 


\section{ZAB-6953}

Ś.P. GABRIEL GAWRYLUK UR. 22-III-1900 R. ZM. 18-V-1975 R. TU SPOCZYWA W BOGU MÓJ DOBRY MĄŻ I NASZ KOCHANY OJCIEC RODZINA POKÓJ JEGO DUSZY

\section{O-2335}

Tu spoczywa w Bogu nasza najmilsza córunia, siostra i wnuczka

Analizowane napisy podkreślają, że życie ziemskie jest kruche i ulotne. W tym kontekście wykorzystywana jest metaforyka światła: życie ludzkie jest gwiazda na niebie, stońcem na niebie [por. Kupiszewski 1986, 32; Borkowski 2000, 349; Marciniak 2008, 191; Kozłowska-Doda 2014, 76]:

\section{BPA-9321}

Ś.P. ANASTAZJA ŁÓJ ŻYŁA LAT 43 ZMARŁA ŚMIERCIĄ TRAGICZNA 8-IX-1942 r. POKÓJ JEJ DUSZY MATKO! ZGASEAŚ NAM JAK GWIAZDKA NA NIEBIE JAK NAM SMUTNO ŻYĆ BEZ CIEBIE DZIECI

\section{KM-1729}

Ś.P. DARIUSZ SZELEST UR. 9-08-1977 R. ZM. 19-08-1977 R. B YEEŚ DLA NAS SEOŃCEM NA NIEBIE BÓG POWOŁAE CIĘ DO SIEBIE

\section{BP-II-3244}

Ś.P. ANNA KADYRKO ŻYŁA LAT 21 ZM. 26. III 1997 SEOŃCE JUZ⿱ ZASZEO A BYE JESZCZE DZIEŃ

Życie jest utożsamiane ze światłem, płomieniem, słońcem itp., śmierć zaś jako jego opozycja kojarzona jest z ciemnością, mrokiem, zimnem, które moga być rozjaśnione przez płomień zapalonego zmarłemu światła; miejsce, gdzie po śmierci trafia człowiek jest określone jako kraj cieni:

\section{KC-I-0050}

Ś.P. PIOTR ŁOSZAK ŻYŁ LAT 33 ZM. DN. 17. V. 1969 R. POKÓJ JEGO DUSZY ZGASŁEŚ MI DROGI SYNU JAK CIEŃ PRZED OCZYMA ACH JAK SMUTNO I TÉSKNO GDY CIEBIE WŚRÓD NAS NIE MA POBUDOWAEA MATKA Z CIEZŻKIM ŻALEM

\section{KL-I-1129}

D. O. M. S. P. WALERI z KARPINSKICH CHLIPALSKIEJ ZGASEEJ

W 18 WIOŚNIE ŻYCIA W D: 19 LUTEGO 1858 R. STROSKANY MĄŻ TEN POMNIK POSTAWIE 


\section{KW-1972}

Ś.P. BEATA KRYSTYNA KUBEL ŻY€A LAT 23 ZM. 15. I. 1997

W MROKU ZAPOMNIENIA NA CHWILE PRZYJDŹCIE i PRZYNIEŚCIE RUMIANKI ZAPALCIE OGNIK ŚWIECY DLA

NICZEGO NIECH ZAPEONIE OGIEŃ DLA ZIMNEGO CIAEA NIECH CZARNE SMUTKI UMRA NA ZAWSZE WIECC NIE WOEAJCIE MNIE Z POWROTEM BO TU JESTEM NAPRAWDE SZCZÉŚLIWA

\section{CH-4635}

WOJCIECH BARTOSZ ŻYŁ 39 LAT ZM. 31. 12. 2003 ZWIĘDŁO JEDNO ŻYCIE W KRAJ ODESZŁO CIENI TYLE SIĘ ODMIENIŁO A ŚWIATA TO NIE ZMIENI

Opozycja życie/śmierć jest wyrażana także przy pomocy symboliki roślinnej: przemijanie życia zostaje wyobrażone jako ginący kwiat, a śmierć to utrwalony w dziełach artystycznych kosiarz, szkielet z kosa, który ścina bez litości najpiękniejsze kwiaty [Borkowski 2000, 349]. Życie - jak kwiat - więdnie (zob. cytowana wcześniej inskrypcja CH-4635); w przytoczonym poniżej epitafium życie doczesne w sposób metaforyczny zostało przedstawione jako kwitnienie rośliny, śmierć zaś oznacza niemożność pełnego rozkwitu:

\section{KC-II-0455}

Б.П. ЕВГЕНІИ КОЦЮБА УР. 20. 10. ІІІ. 1929 Р. ПОМ. 15. ХІІ. 1943

Р. НА СВІТІ ЦВІТОМ И НЕРОХЦВІВСЯ ДО СЕБІ МОГИЛА ЗАБРАЛА МОЯ МАМА НЕЗАБУДКИ [?] І МОГИЛУ МОЮ УКРАШАЛА ГІРКІ СЛЬОЗИ СВОЇ ПРОЛІВАЛА ПОКІЙ ЕГО ДУШІ

W licznych inskrypcjach podkreśla się, że życie doczesne zmarłego było trudne, pełne znoju, że doznał on wielu cierpień, doświadczył długich/ciężkich chorób itp.:

\section{O-2393}

Ś.P. NADZIEJA KORNELUK UR. DN. 1-IV-1944 ZM. DN. 10-IX-1978 r ŻYŁAŚ MAŁO CIERPIAŁAŚ WIELE ŻYJ Z BOGIEM MÓJ MIŁY ANIELE POGRĄŻONA W ŻALU - RODZINA

\section{K-2118}

Ś.P. ANTONI RYCHLIK ŻYŁ LAT 77 ZM. 23-06-1987 R. Ś.P. JÓZEF RYCHLIK ZY€ LAT 69 ZM. 14-07-1986 R. Ś.P. ODESZLI, LECZ DUCHEM POZOSTALI Z NAMI TRUD, ZNÓJ I MIŁOŚĆ DALI NAM Z SIEBIE. WPROWADŹ ICH PANIE DO WIECZNOŚCI BRAMY A NAM WSKAŻ DROGĘ PRZEZ NICH - DO CIEBIE 


\section{DCZE-2437}

Ś.P. JAN SEGIEŃ ŻYŁ LAT 67 ZM. 3-IX-1973 r. PO DŁUGIEJ I CIĘŻKIEJ CHOROBIE POKÓJ JEGO DUSZY

\section{CHKA-7266}

KUKAWSKI DYMITR UR DN 06 XII 1924 R ZM DN 7 V 1967 R ZMARE PO CIĘŻKIEJ CHOROBIE POKÓJ JEGO DUSZY

Analizowany materiał pokazuje, że nadawcy inskrypcji zwracają uwage na fakt, iż życie było zbyt krótkie, zgon zaś przedwczesny, co wyraża się m.in. poprzez używanie przysłówków niedługo, przedwcześnie, szybko, nagle, mato:

\section{BP-I-2888}

Ś.P. JAN SEWASTIANIUK ŻYŁ LAT 19 ZM. DN. 7-V-1984 r. POKÓJ JEGO DUSZY ACH DROGI JANKU NIE DŁUGO NAM ŻYŁEŚ I W MŁODYM WIEKU ŻYCIE SKOŃCZYŁEŚ ODSZEDEEŚS NAM Z ZIEMI I ŻYJESZ W NIEBIE A NASZE SERCA TĘSKNIĄ DO CIEBIE

\section{BP-I-2971}

O WIELKOŚCI TEGO CZŁOWIEKA ŚWIADCZĄ JEGO CZYNY

CAŁE ŻYCIE POŚWIECIŁ PRACY. ŻYŁ SZYBKO ODSZEDŁ

PRZEDWCZEŚNIE POZOSTAWIAJĄC SMUTEK I ŻAL

W NASZYCH SERCACH ŻONA Z CÓRKAMI

DCZE-2550

Ś.P. ANNA WASZCZUK z /d/ GAWRYLUK żyła lat 81 zm. 22. 12. $2002 \mathrm{r}$. Pokój jej duszy BYŁAM WŚRÓD WAS SZYBKO NADSZEDE CZAS NA WIEKU PRZEGNAĆ WAS

\section{TOL-8141}

Ś.P. Kuroczkin Jan żył lat 19 zmarł śmiercią tragiczną dnia 10. I. 1965 r. Janku... Odszedłeś tak nagle żal w sercu się mieści, zabrałeś wszystko nie wziołeś boleści. Kochanemu synowi i bratu Rodzice i siostra

\section{KW-1953}

Ś.P. JAN PAŃKOWSKI ZMARE ŚMIERCIĄ TRAGICZNĄ 15-V-1983 r. O DOBRY JEZU A NASZ PANIE TY JESTEŚ ŻYWOT I ZMARTWYCHWSTANIE WEŹ DUSZE SYNKA NASZEGO DO KRÓLESTWA OJCA SWEGO POKÓJ TWEJ DUSZY KOCHANY NASZ SYNKU MÓJ DROGI BRACISZKU ŻYEEŚ TAK MAEO SYNKU NASZ MIEY W CIEZŻKIEJ ŻAEOBIE NAS ZOSTAWIEEŚS CZY LOS TWÓJ TAKI CZY PRZEZNACZENIE POZOSTAE DLA NAS PO TOBIE BÓL I CIERPIENIE 
Analiza inskrypcji pokazuje, że życie ziemskie jest krótkie, pełne cierpień i trudów, śmierć zaś otwiera przed człowiekiem spokój, ciszę i odpoczynek. Takie chrześcijańskie przekonanie odzwierciedlają liczne napisy zawierające eufemizmy śmierci, czyli zastępcze środki językowe używane zamiast takiego wyrazu, wyrażenia lub zwrotu, który z różnych względów nie może być wprowadzony do wypowiedzi [Dąbrowska 1991, 131]; wiąże się to z tabuizowaniem zjawiska śmierci. W napisach nagrobnych często spotykane są zastępcze środki językowe, określane za Anną Engelking jako metafory tamtego świata [Engelking 1984, 121]. Eufemizmy śmierci zawierają czasowniki spoczać/spoczywać, odpoczywać, rzeczowniki odpoczywanie, odpoczynek, pokój, spokój, cisza, np.

\section{J3-706}

Ś.P. ZOFIJA TEMOSZUK PRZEŻYŁA LAT 48 ZMARŁA

3 PAŹDZIERNIKA 1944 SPOCZYWA W ŁASCE BOGA

\section{CH-4410}

Ś.P. MARJA TRYBALSKA ŻYŁA LAT 17 ZM. 11 MAJA 1920 R.

WIECZNE ODPOCZYWANIE RACZ IM DAĆ PANIE DROGIEMU MĘŻOWI UKOCHANYM DZIECIOM I SIOSTRZE NA WIECZNĄ PAMIĄTKĘ KAMIEŃ TEN KŁADZIE - ŻONA, MATKA

\section{RA-3942}

Ś.P. SAWICCY JÓZEF UR. 1907 ZM. 1966 KATARZYNA UR. 1910 ZM. 1985 DZIECI JÓZIO ZOSIA MARYSIA NIECH ODPOCZYWAJA W POKOJU

\section{KM-1420}

Ś.P. PIOTR PROKOPIUK ŻYŁ LA 53 ZM. 1-VI-1938 R. ZOFIA PROKOPIUK ŻYŁA LAT 95 ZM. 11-VII-1985 R. ZE ŚWIĘTYMI DAJ IM PANIE ODPOCZYNEK

\section{TOL-8143}

Ś.P. MARIA KALISZUK ŻYŁA LAT 67 ZM. DN. 19.9.1939 R. BAZYLI KALISZUK ŻYŁ LAT 54 ZM.DN.3.5.1925 R. WIECZNY POKÓJ RACZ IM DAĆ BOŻE RODZICE

Środkiem stylistycznym, często wykorzystywanym w napisach nagrobnych, jest metonimia zawierająca leksemy grób i mogiła, oznaczająca przeniesienie na proces umierania nazw poszczególnych etapów i rekwizytów obrzędu pogrzebowego [Marciniak 2008, 195]. Analizowany materiał pokazuje, że leksemy grób i mogiła wchodzą w skład licznych określeń zastępczych śmierci w połączeniu z czasownikami leżeć/lec, mieścić się, złożyć, spać: 


\section{M-II-398}

Ś.P. TEODOR SAMOSZUK * 8. 6. 1946 † 4. 11. 1978 ODSZEDEEŚ OD

NAS I LEŻYSZ W GROBIE A NAM POZOSTAŁ SMUTEK PO TOBIE

\section{TOL-8165}

Ś.P. HENADI GRYGOROWICZ ŻYŁ LAT 15 ZM. 1946 R.

ŚMIERCIA TRAGICZNĄ DROGIEMU SYNOWI I KOCHANEMU BRATU POGRĄŻENI W GEĘBOKIM SMUTKU RODZICE I SIOSTRY PSZYCHODZE ${ }^{4}$ WESTCHNĄĆ NA MOGIEE

W KTÓREJ SPOCZYWASZ SYNU DROGI ACH ZNIKŁY JASNE SZCZEŚSCIA CHWILE ODKĄD ŚMIERĆ WESZŁA W NASZE DROGI O NAJDROŻSZY NASZ LEGEEŚ W MOGILE NIE POMOGĄ NI ŻALE JĘKI I ROZPACZE JUŻ CIĘ MÓJ SYNU NIE ZOBACZE

\section{KC-I-0055}

Ś.P. WŁODZIMIERZ HORDYCZKO ŻYŁ LAT 22 ZM. DN. 26 IV 1970 R CO MIELIŚMY NAJDROŻSZEGO W TYM GROBIE SIE MIEŚCI ŚMIERĆ WSZYSTKO ZABRAŁA NIE WZIĘŁA BOLEŚCI POKÓJ JEGO DUSZY KOCHANEMU SYNOWI RODZICE I SIOSTRA

\section{M-I-085}

Ś.P. WŁODZIMIERZ URYNIUK ŻYŁ LAT 16 ZM. SM. TRAG. DN. 8-VIII-1982 R CO MIELIŚMY NAJDROŻSZEGO ZEOŻYLIŚMY W TYM GROBIE TYLKO ŻAL I SMUTEK POZOSTAE NAM PO TOBIE RODZINA POKÓJ JEGO DUSZY

\section{KL-I-995}

Ś.P. WŁODZIMIERZ IWANIUK ŻYŁ LAT 9 ZMARE ŚMIERCIĄ TRAGICZNA 28-X-1975 R. ŻYEEŚ NAM KRÓTKO, CIERPIAEEŚ WIELE ŚPISZ W CIEMNEJ MOGILE NASZ DROGI ANIELE

W wyobrażeniach o życiu pośmiertnym grób staje się synonimem domu, który jest postrzegany jako „swoja” przestrzeń ${ }^{5}$ [Седакова 1983, 208-209]. Traktowanie grobu jako domu jest nawiązaniem do zdań z Pisma Świętego: Zdażać będzie człowiek do swego wiecznego domu (Koh. 12, 5); A groby ich będa im domami na wieki (Ps. 48, 12 - Wlg) [Kolbuszewski 1996, 49]. Znajduje to odzwierciedlenie w inskrypcjach zawierajacych leksem dom, w których na zasadzie zestawień antonimicznych utworzonych poprzez wyrażenia $w$ domu/w gościnie zawarto przejęte z tradycji biblijnej przekonanie o tym, że życie jest tylko procesem przejściowym, przebywaniem „w gościnie”, śmierć zaś oznacza pobyt „w domu” [por. Dudek-Szumigaj 2008, 207]:

\footnotetext{
4 Ortografia zgodna z zapisem na nagrobku.

5 Jak zaznacza Olga Sedakowa, nazwy grobu sa tworzone od rdzenia дом poprzez afiksację (nр. домик, домовина, домовка, домовище) [Седакова 1983, 208].
} 


\section{DCZE-2549}

Ś.P. MIKOŁAJ WASZCZUK ŻYŁ LAT 83 ZM. DN. 1-X-1994 R. POKÓJ JEGO DUSZY CO MNIE SPOTKAŁO I WAS NIE MINIE JA JESTEM JUŻ W DOMU A WY W GOŚCINIE

\section{KYN-7719}

Ś.P. KONSTANTY ZAJKO ŻYŁ LAT 49 ZM. 27-IV-1995 R. POKÓJ JEGO DUSZY CO MNIE SPOTKAEO TO WAS NIE MINIE JA JESTEM W DOMU A WY W GOŚCINIE

W analizowanym materiale odnaleziono również inskrypcje ukraińskojęzyczne zawierające leksem xama 'dom', a także inskrypcję ukraińskojęzyczną i rosyjskojęzyczną z leksemem обитель 'schronienie, przybytek, zakątek', który również należy zaliczyć do pola semantycznego 'dom': chrześcijańskie wyobrażenie na temat grobu jako bożego domu wiecznego dodatkowo wzmacniają określenia вічна обитель, святая обитель:

\section{KC-II-0456}

В.П. ФЕДОР КОЦЮБА УРОДИВСЯ 28 СТИЧНЯ 1906 Р ПРОЖИЛ 73 ЛЕТ ПОМЕР 16-VII-1979 ЗБУДУВАВЕМ СОБИ ВЛАСНУ ХАТУ СПОКИЙНО В НИЙ БУДУ СПОЧИВАТИ НИ БУДУ ДО СИНА МОГИЛЫ ХОДИТЫ НИ БУДУ БИЛШ СВИТЛА СВИТЫТЫ ПОКУЙ ЕГО ДУШЕ

\section{KC-II-0490}

ТЕКЛЯ МОНЮК 3 РОДУ СІДОРУК ЖІЛА 60 ЛІТ 25 МАРТ 7 КВ 1933 ОДОІ ШЛА ДО ВІЧ НОІ ОБИ ТЕЛІ БЛАЖЕНОГО ОДПОЧІНКУ З ВЕЛІКОІ ГОРЕ- СТІ МУЖ І ДІТИ 1935

\section{J3-674}

ЗДЕСЬ ПОКОИТСЯ ПРАХ РАБА БОЖІЯ ВІКТОРА ПЕТРУЧУКА УМ. ТРАГИЧЕСКУЮ СМЕРТІЮ ДН. І. 9. 1946 ПРОЖКЛ 20 ЛЕТ СПИ ДИТЯ МОЕ НЕЗАБВЕН НОЕ В СТЕНАХ ОБИТЕЛИ СВЯТОЙ НАСТАНЕТ ЧАС БЛАГОСЛОВЕННЫИ И МЫ УВИДИМСЯ С ТОБОЙ

Liczne inskrypcje odzwierciedlają chrześcijańskie rozumienie życia i śmierci, zgodnie z którym eksponuje się przełomowy charakter zgonu, uwypukla przejście w inny wymiar czasowy $\mathrm{z}$ czasu rozumianego w wymiarze doczesnym do wieczności, a więc czasu mistycznego, boskiego [Borkowski 2000, 349], śmierć jest więc początkiem życia wiecznego, w niebie, w królestwie niebieskim, np.

\section{RA-3966}

Ś.P. MARIA MAKSYMIUK ŻYŁA LAT 74 ZM. D. 13 IV 1975 R. „MY WIEMY, ŻE PRZESZLIŚMY ZE ŚMIERCI DO ŻYWOTA" 


\section{BP-I-2888}

Ś.P. JAN SEWASTIANIUK ŻYŁ LAT 19 ZM. DN. 7-V-1984 r. POKÓJ JEGO DUSZY ACH DROGI JANKU NIE DŁUGO NAM ŻYŁEŚ I W MŁODYM WIEKU ŻYCIE SKOŃCZYŁEŚ ODSZEDŁEŚ NAM Z ZIEMI I ŻYJESZ W NIEBIE A NASZE SERCA TĘSKNIĄ DO CIEBIE

\section{KL-I-1167}

JADWINIA MALENKA PROSI BOŹI ABY DZIADUNIA I BABUNIE ORAZ WUJASZKA WPROWADZIĆ RACZYŁ. DO KRÓLESTWA NIEBIESKIEGO. ZA DUSZE JÓZEFY PIOTRA I WŁODZIMIERZA PROSIEMY O NABOŻNE WESTCHNIENIE

$$
* * *
$$

Przeanalizowane inskrypcje ze wschodniej Lubelszczyzny pozwalają na odtworzenie wybranych istotnych aspektów życia doczesnego zmarłych oraz wizję życia pozagrobowego. Wiele napisów odwołuje się do aksjologii rodzinnej, o czym świadczy podawanie w epitafiach nazw stopni pokrewieństwa, czasem w formie hipokorystycznej; nazwy te są często opatrzone pozytywnie wartościującymi i emocjonalnie zabarwionymi określeniami. W licznych inskrypcjach życie i śmierć funkcjonują jako człony opozycji: życie jest utożsamiane ze światłem (słońce, gwiazda), śmierć zaś to „kraina cieni”, mrok, ciemność, chłód. Kolejna wizja życia i śmierci nawiązuje do metaforyki roślinnej: życie jest jak kwiat, który nie mógł rozkwitnąć, śmierć jest postrzegana jako więdnięcie. Wielu nadawców inskrypcji podkreśla, że życie doczesne zmarłego było trudne, pełne cierpień i zostało przerwane nagle, zbyt wcześnie. Śmierć jest więc stanem odpoczynku, spokoju i ciszy. Spotykane w analizowanych napisach eufemizmy śmierci skonstruowane wokół leksemów grób, mogita, dom, xama обитель odwołują się do chrześcijańskiej wizji śmierci jako powrotu do domu wiecznego. Śmierć, jak pokazuje analizowany materiał, nie jest definitywnym końcem życia, ale przejściem w inny - wieczny - wymiar istnienia.

\section{Literatura}

Borkowski I., 2000, Śmierci tajemnicze wrota. Jezykowy świat inskrypcji nagrobnych, „Język a kultura”, t. 13, Wrocław, s. 343-354.

Czyżewski F., 2013, Antroponimia pogranicza polsko-wschodniostowiańskiego w świetle inskrypcji nagrobnych, Lublin. 
Dąbrowska A., 1991, Kwalifikowanie eufemizmów przez niektóre wspótczesne słowniki jezzyka polskiego, [w:] Język a kultura. Podstawowe pojęcia i problemy, red. J. Anusiewicz i J. Bartmiński, Wrocław, s. 131-136.

Długosz 2010 - K. Długosz, Inskrypcje nagrobne w ujęciu językoznawczym, Gorzów Wielkopolski.

Dudek-Szumigaj A., 2008, Eufemizmy śmierci w świetle inskrypcji nagrobnych wybranych nekropolii prawostawnych Wolynia, [w:] Tabu językowe i eufemizacja w dialektach słowianskich, red. F. Czyżewski, A. Tyrpa, Lublin, s. 201-209.

Dudek-Szumigaj A., 2011, Postrzeganie śmierci w świetle inskrypcji nagrobnych nekropolii prawosławnych pogranicza polsko-ukrainskiego, [w:] Nekropolie jako znak kultury pogranicza polsko-wschodniostowiańskiego, red. F. Czyżewski, A. Dudek-Szumigaj, L. Frolak, Lublin, s. 67-74.

Dudek-Szumigaj A., 2014, Funkcja ekspresywna inskrypcji nagrobnych (na przyktadzie nekropolii prawostawnych pogranicza polsko-ukrainskiego), [w:] Cmentarze po obu stronach Bugu, red. H. Arkuszyn, F. Czyżewski, A. Dudek-Szumigaj, Włodawa-Lublin, s. 177-190.

Engelking A., 1984, Istota i ewolucja eufemizmów (na przykładzie zastępczych określeń śmierci), „Przegląd Humanistyczny” t. 4, s. 115-129.

Kolbuszewski J., 1996, Cmentarze, Wrocław.

Kozłowska-Doda J., 2014, U dalokuju staronku odjeżdżasz, czyli odbicie tradycyjnej metaforyki śmierci w tekstach obrzędowych i opowieściach Polaków $z$ Woronowszczyzny, [w:] Cmentarze po obu stronach Bugu, red. H. Arkuszyn, F. Czyżewski, A. Dudek-Szumigaj, Włodawa-Lublin, s. 71-84.

Kupiszewski W., 1986, Groby mówia, „Literatura Ludowa” 1986, nr 2, s. 27-47.

Marciniak R., 2008, Określenia śmierci $i$ umierania w inskrypcjach nagrobnych cmentarzy w Łowiczu i Ztakowie Kościelnym, [w:] Tabu językowe i eufemizacja w dialektach słowiańskich, red. F. Czyżewski, A. Tyrpa, Lublin, s. $181-200$.

Steczko I., 2011, Portret funeralny mężczyzny w świetle XIX-wiecznych inskrypcji nagrobnych z cmentarza Rakowickiego w Krakowie, „Prace Komisji Językoznawczej BTN" Nr XXI-2011, s. 17-29.

Седакова О.А, 1983, Метафорическая лексика погребального обряда. Материальг $\kappa$ словарю, „Славянское и балканское языкознание. Проблемы лексикологии", вып. 8, под ред. Л.Н. Смирнова, Москва, с. 204-221.

\section{Rozwiązanie skrótów nekropolii prawosławnych, z których pochodzą analizowane inskrypcje nagrobne}

\footnotetext{
BP - Biała Podlaska, powiat bialski

$\mathrm{CH}$ - Chełm, powiat chełmski

CHKA - Choroszczynka, powiat bialska

DCZE - Dobratycze, powiat bialski

J - Jabłeczna, powiat bialski
} 
$\mathrm{KC} \quad-$ Kodeniec, powiat parczewski

KL - Kobylany, powiat bialski

KM - Kostomłoty, powiat bialski

KW - Kopytów, powiat bialski

KYN - Koroszczyn, powiat bialski

M - Międzyleś, powiat bialski

O - Okczyn, powiat bialski

RA - Ruda, powiat chełmski

TOL - Terespol, powiat bialski

ZAB - Zabłocie, powiat bialski

LIFE AND DEATH IN LIGHT OF TOMBSTONE INSCRIPTIONS

IN ORTHODOX NECROPOLISES IN EASTERN LUBLIN REGION

S U M M A R Y

The analyzed inscriptions in the eastern Lublin region enable reconstruction of selected essential aspects of the worldly life of the deceased. On the basis of gravestone inscriptions in the Orthodox cementeries in the Lublin region the author tries to reconstruct the ways of perceiving life and death, reflected in the inscriptions. Many inscriptions reflect Christian beliefs about eternal life and resurrection; they describe death as a stage of waiting for as sleeping, rest, and as silence. 